\title{
Genetic diversity analysis of an indigenous Chinese buffalo breed and hybrids based on microsatellite data
}

\author{
W.C. Yang ${ }^{1}$ K.Q. Tang ${ }^{1}$, J. Mei $^{2}$, W.B. Zeng ${ }^{3}$ and L.G. Yang ${ }^{1}$ \\ ${ }^{1}$ Key Laboratory of Agricultural Animal Genetics, Breeding and Reproduction, \\ Ministry of Education, Huazhong Agricultural University, Wuhan, P.R. China \\ ${ }^{2}$ Hubei Bull Station, Wuhan, P.R. China \\ ${ }^{3}$ Hubei Jin Niu Husbandry Co. Ltd., Jingmen, China \\ Corresponding author: L.G. Yang \\ E-mail: yangliguo2006@yahoo.com.cn
}

Genet. Mol. Res. 10 (4): 3421-3426 (2011)

Received April 8, 2011

Accepted August 15, 2011

Published December 5, 2011

DOI http://dx.doi.org/10.4238/2011.December.5.1

\begin{abstract}
Chinese native buffaloes have faced the threat of extinction, along with an increase in crossbreeding with domesticated river buffaloes; consequently, conservation of local buffalo genetic resources has become a priority. A Chinese native breed, Jianghan, is often crossed intentionally and unintentionally with imported breeds from India and Pakistan, Murrah, and Nili-Ravi. A total of 128 buffaloes of the breeds Jianghan, Murrah, and Nili-Ravi and their presumed hybrid offspring were genotyped for 10 microsatellite markers. Heterozygosity and Wright's F-statistics were calculated to determine the genetic variation in those populations. The observed average heterozygosities ranged from 0.836 (Murrah) to 0.986 (Jianghan), higher than the expected heterozygosities and all the inbreeding values within the populations were negative. The genetic distances between the presumed hybrid buffaloes and the two imported river type dairy buffalo breeds (Murrah and Nili-Ravi) were lower than with the native Jianghan, indicating strong contributions of the imported breeds to this presumed hybrid buffalo population. This information will be useful for
\end{abstract}


the development of rational breeding for the dairy buffalo industry and for conservation strategies for the Jianghan buffalo.

Key words: Chinese indigenous buffalo; Microsatellite; Conservation; Hybrid offspring

\section{INTRODUCTION}

The water buffalo (Bubalus bubalis) contributes significantly to the agricultural economy and food security of southern China and countries in Southeast Asia. It contributes through milk, meat, hides, and draught power. Chinese indigenous buffaloes are of swamp type, historically employed primarily as a work animal since their milk production is very low with an annual milk yield of 500-700 kg (Yang et al., 2007). Therefore, the well-known rivertype dairy buffalo breeds Murrah and Nili-Ravi, were introduced from India and Pakistan in 1957 and 1974, respectively, to crossbreed with local buffalo. After decades of research and practice, more than 1 million crossbred buffaloes have been born, and milk production has been as high as $1200-2000 \mathrm{~kg}$, but most of them are scattered in countryside due to a lack of systematic recording keeping. In recent years, the Chinese government increased the input in the dairy buffalo industry and the nation put forward that buffalo milk industry is a new growth point for the country's economy, which has promoted the development of the buffalo milk industry (Huang and Huang, 2006). However, the Chinese native buffalo faces the threat of extinction with the increase in crossbred buffaloes, and the conservation of local buffalo genetic resources has been a priority topic in many discussions. Herein, we used 10 microsatellite markers to analyze the genetic structure of Jianghan buffalo of an indigenous Chinese buffalo breed to lay the foundation for rational breeding in the dairy buffalo industry and conservation strategies for Jianghan buffalo.

\section{MATERIAL AND METHODS}

\section{Sample collection for DNA analysis}

A total of 128 buffaloes from four populations were examined in this study. The sperm from 15 Murrah buffalo and 31 Nili-Ravi buffalo obtained from the Bull Station in Hubei Province. Blood samples were obtained from 30 Jianghan buffalo from several villages located in remote areas in Jingmen County and from 52 assumed hybrid buffalo from Jingzhou city, Hubei province of China. Genomic DNA was extracted from the sperm or blood using the standard phenol-chloroform extraction protocol. The DNA samples were dissolved in TE buffer, consisting of $10 \mathrm{mM}$ Tris- $\mathrm{Cl}(\mathrm{pH} \mathrm{7.5)}$ and $1 \mathrm{mM}$ EDTA (pH 8.0), and were stored at $-20^{\circ} \mathrm{C}$ for use.

\section{Selection of microsatellites and PCR amplification}

The microsatellite markers used in this study were chosen according to a recommendation from a joint meeting between the International Society of Animal Genetics (ISAG) and FAO (Hoffmann et al., 2004) for genetic diversity studies. A total of 10 heterologous 
microsatellite loci were chosen for the study. These loci were BM2113, ETH225, BM1862, TGLA53, BMS510, BM1824, BM1818, CSSM019, ILSTS030 and ILS058. The PCR conditions were standardized for all 10 primer pairs selected for the study. Polymerase chain reaction (PCR) was performed in a $20-\mu \mathrm{L}$ mixture containing 10 pmol primers, $200 \mu \mathrm{M}$ dNTPs (deoxyribonucleotide triphosphates), $2 \mu \mathrm{L} 10 \mathrm{X}$ reaction buffer consisting of $1.5 \mathrm{mM} \mathrm{MgCl}$, $0.5 \mathrm{U}$ Taq-DNA polymerase (Promega, Madison, WI), and $50 \mathrm{ng}$ genomic DNA as template. After denaturation at $94^{\circ} \mathrm{C}$ for $5 \mathrm{~min}$ followed by 34 cycles of $94^{\circ} \mathrm{C}$ for $45 \mathrm{~s}, 55^{\circ}$ to $64^{\circ} \mathrm{C}$ (primer specific) for $45 \mathrm{~s}$, and extension at $72^{\circ} \mathrm{C}$ for $45 \mathrm{~s}$. The final cycle was followed by an extension step at $72^{\circ} \mathrm{C}$ for another $10 \mathrm{~min}$. PCR products were separated by $8 \%$ PAGE (acrylamide:bisacrylamide $=29: 1$ ) gel electrophoresis, and fragment sizing was done using the GENESCAN (3.1) and GENOTYPE software.

\section{Data analysis}

To determine the genetic variation within and between breeds, parameters such as heterozygosity and Wright's F-statistics $\left(\mathrm{F}_{\mathrm{ST}}, \mathrm{F}_{\mathrm{IS}}\right.$, and $\left.\mathrm{F}_{\mathrm{IT}}\right)$ were calculated. The number of alleles and allele frequencies and Hardy-Weinberg equilibrium were determined using GENEPOP (Version 3.3) (Raymond and Rousset, 1995). The effective number of alleles was estimated according to Kimura and Crow's (1964) formula. The Genes in Population (Version 2.0) software (May et al., 1995) was used to analyze Wright's F-statistic, expected heterozygosity (He), and observed heterozygosity (Ho) in each population. Nei's DA genetic distances (Nei, 1978) were calculated and then used to construct the neighbor-joining tree using the DISPAN package (Ota, 1993).

\section{RESULTS}

\section{Allele frequencies, heterozygosity, and F-statistics}

Allele frequencies are available from the corresponding author upon request. Observed heterozygosity $\left(\mathrm{H}_{\mathrm{S}}\right)$, expected heterozygosity $\left(\mathrm{H}_{\mathrm{T}}\right)$, Wright's F-statistics $\left(\mathrm{F}_{\mathrm{IS}}, \mathrm{F}_{\mathrm{IT}}\right.$, and $\left.\mathrm{F}_{\mathrm{ST}}\right)$ at each locus are all shown in Table 1. The number of alleles per locus varied from 3 to 11, which indicated that all the microsatellites used were suitable for genetic diversity analysis. The $\mathrm{H}_{\mathrm{T}}$ varied from 0 (TGLA53) to 0.618 (BM1818). The $\mathrm{F}_{\mathrm{ST}}$ per locus varied from 0 (ETH225, TGLA53 and BM1824) to 0.881 (BM1862), and the average $\mathrm{F}_{\mathrm{ST}}$ of all loci was 0.177. Multilocus $\mathrm{F}_{\mathrm{ST}}$ values indicated that around $17.7 \%$ of the total genetic variation was explained by population differences, with the remaining $82.8 \%$ corresponding to differences between individuals within population. The HWE test showed that all loci deviated from HWE when analyzed across populations. These deviations are likely caused by the small effective population sizes and the difficulties in collecting enough unrelated individuals. Mean observed heterozygosity $\left(\mathrm{H}_{\mathrm{O}}\right)$, mean expected heterozygosity $\left(\mathrm{H}_{\mathrm{E}}\right)$, mean polymorphic information content (PIC) and mean observed number of alleles, as well as the mean effective number of alleles for all populations and the observed data for inbreeding within the different populations $\left(\mathrm{F}_{\mathrm{IS}}\right)$ are presented in Table 2. Although varying between populations, the observed mean heterozygosity was higher than the expected mean heterozygosity for all populations, and all the values of inbreeding within the populations were negative. 
Table 1. Source of populations, sample size, mean observed (Ho) and expected (Ho) heterozygosities, mean number of alleles, mean polymorphic information content (PIC), Wright's $F$-statistics $\left(\mathrm{F}_{\text {IS }}\right)$, and number of loci deviating $(\mathrm{P}<0.01)$ from Hardy-Weinberg equilibrium $(\mathrm{HWE})$ in each buffalo population.

\begin{tabular}{|c|c|c|c|c|c|c|c|c|}
\hline \multirow[t]{2}{*}{ Population } & \multirow[t]{2}{*}{ No. } & \multicolumn{2}{|c|}{ Mean heterozygosity } & \multirow[t]{2}{*}{ PIC } & \multirow[t]{2}{*}{$\mathrm{F}_{\mathrm{IS}}$} & \multicolumn{2}{|c|}{ Mean number of alleles } & \multirow[t]{2}{*}{ No. of loci not in HWE } \\
\hline & & Ho & $\mathrm{He}$ & & & Observed & Effective & \\
\hline Nili-Ravi & 31 & 0.852 & 0.647 & 0.573 & -0.486 & 4.900 & 2.230 & 6 \\
\hline Murrah & 15 & 0.836 & 0.581 & 0.469 & -0.501 & 3.100 & 1.660 & 4 \\
\hline Hybrid & 52 & 0.877 & 0.701 & 0.641 & -0.533 & 6.500 & 3.170 & 5 \\
\hline Jianghan & 30 & 0.986 & 0.734 & 0.671 & -0.490 & 5.800 & 2.150 & 9 \\
\hline
\end{tabular}

Table 2. Number of microsatellite alleles observed, observed heterozygosity $\left(\mathrm{H}_{\mathrm{s}}\right)$, expected heterozygosity $\left(\mathrm{H}_{\mathrm{T}}\right)$, F-statistics $\left(\mathrm{F}_{\mathrm{IS}}, \mathrm{F}_{\mathrm{IT}}\right.$, and $\left.\mathrm{F}_{\mathrm{ST}}\right)$ at each locus, and number of populations deviating from Hardy-Weinberg equilibrium (HWE).

\begin{tabular}{lccccccc}
\hline Locus & No. of alleles & $\mathrm{H}_{\mathrm{T}}$ & $\mathrm{H}_{\mathrm{S}}$ & $\mathrm{F}_{\mathrm{IS}}$ & $\mathrm{F}_{\mathrm{IT}}$ & $\mathrm{F}_{\mathrm{ST}}$ & Populations not in HWE \\
\hline BM2113 & 11 & 0.563 & 0.555 & -0.801 & -0.777 & 0.013 & 4 \\
ETH225 & 3 & 0.500 & 0.500 & -1 & -1 & 0.000 & 3 \\
BM1862 & 8 & 0.400 & 0.048 & 1 & 1 & 0.881 & 4 \\
TGLA53 & 10 & 0.000 & 0.000 & 0.000 & 0.000 & 0.000 & 2 \\
BMS510 & 9 & 0.571 & 0.568 & -0.65 & -0.644 & 0.004 & 4 \\
BM1824 & 6 & 0.500 & 0.500 & -1 & 1 & 0.000 & 3 \\
BM1818 & 7 & 0.618 & 0.580 & -0.723 & -0.617 & 0.062 & 3 \\
CSSM019 & 9 & 0.482 & 0.416 & -0.895 & -0.635 & 0.138 & 3 \\
ILSTS030 & 11 & 0.28 & 0.122 & 1 & 1 & 0.567 & 4 \\
ILS058 & 9 & 0.088 & 0.078 & 0.324 & 0.396 & 0.107 & 3.2 \\
Average & 8.3 & 0.400 & 0.337 & -0.275 & -0.228 & 0.177 & \\
\hline
\end{tabular}

\section{Genetic distance}

Nei's (1972) standard genetic distance of the 4 populations is listed in Table 3. The genetic distance between the assumed hybrid buffalo population and two well-known rivertype dairy buffalo breeds, Murrah and Nili-Ravi, was lower than that between the hybrids and Jianghan buffalo (Table 3 ). The greatest genetic distance was 0.230 , between Jianghan buffalo and Murrah buffalo. The dendrogram illustrating the relationship between these populations is shown in Figure 1. Murrah buffalo and Nili-Ravi buffalo clustered the most closely, and the next most closely related breed was with the assumed hybrid buffalo.

Table 3. Matrix of Nei's (1978) standard genetic distance among four buffalo populations.

\begin{tabular}{lcccc}
\hline & Jianghan & Hybrid & Nili-Ravi & Murrah \\
\hline Jianghan & 0.000 & & & \\
Hybrid & 0.172 & 0.000 & 0.000 & 0.057 \\
Nili-Ravi & 0.199 & 0.048 & 0.113 & 0.000 \\
Murrah & 0.230 & &
\end{tabular}

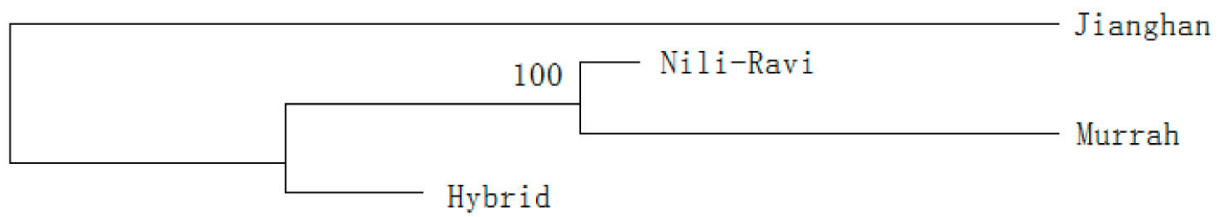

Figure 1. Neighbor-joining (NJ) tree of two Chinese indigenous buffalo populations and two introduced river buffalo breeds. 


\section{DISCUSSION}

The mean allele number and heterozygosity were used as estimators to evaluate genetic characteristics and diversity. In the present study, the mean expected heterozygosity for Jianghan and assumed hybrid buffalo populations were 0.701 and 0.734 , which was higher than those of Southeast Asian swamp buffalo (0.506) (Barker et al., 1997; Zhang et al., 2007). This may be due to low selection pressure in the indigenous Chinese breeds because of the lack of improvement programs and indicated that these two buffalo populations had abundant genetic resources. The mean expected heterozygosity for Murrah and Nili-Ravi buffalo populations were 0.581 and 0.647 , which were lower than those of river buffalo in India (0.71-0.78, Kumar et al., 2006). The low genetic diversity in Murrah and Nili-Ravi buffalo populations in our study may be explained by the use of high selection pressure for milk production traits. In this study, the observed mean heterozygosity was higher than the expected mean heterozygosity for all populations, and all the inbreeding values within the populations were negative, indicating the absence of inbreeding within those populations. The mean PI content in different local populations in this study was between 0.469 and 0.671 , with Murrah the lowest and Jianghan Spotted the highest. The high PI content of Jianghan may be due to the lower selection pressure in this breed.

The genetic distance between assumed hybrid buffalo population and two well-known river- type dairy buffalo breeds, Murrah and Nili-Ravi, was lower than that between the hybrids and Jianghan buffalo. This could be explained by the existence of many hybrid offspring in the assumed hybrid buffalo population, due to the introduction of Murrah and Nili-Ravi to this region from India and Pakistan in 1957 and 1974, respectively. The highest genetic distance was 0.230 between Jianghan buffalo and Murrah buffalo. This is expected due to the long geographical distance between these two buffalo. The dendrogram illustrating the relationship between these populations is shown in Figure 1. Murrah buffalo and Nili-Ravi buffalo cluster the most closely; their close relationship is consistent with their geographical proximity and their characterization river-type dairy buffalo breed. The next most closely related breed is the assumed hybrid buffalo which consisted of many hybrid offspring between Jianghan buffalo and the two well-known river-type dairy buffalo breeds, Murrah and Nili-Ravi. This result implies that there are many potential resources for dairy buffalo breeding in the country.

In conclusion, we present here the first study of genetic diversity of Jianghan buffalo using microsatellite markers recommended by FAO and ISAG. The results indicate abundant genetic variation and the absence of inbreeding within the populations. These findings will be useful for the development of rational breeding in the dairy buffalo industry and conservation strategies for Jianghan buffalo.

\section{ACKNOWLEDGMENTS}

Research supported by both the National Key Technology R\&D Program (\#2008BADB2B09-05) and the earmarked fund for Modern Agro-Industry Technology Research System (\#nycytx-10).

\section{REFERENCES}

Arora R, Lakhchaura BD, Prasad RB, Tantia MS, et al. (2004). Genetic diveristy analysis of two buffalo populations of 
northern India using microsatellite markers. J. Anim. Breed. Genet. 121: 111-118.

Barker JSF, Moore SS, Hetzel DJS, Evans D, et al. (1997). Genetic diversity of Asian water buffalo (Bubalus bubalis): microsatellite variation and a comparison with protein-coding loci. Anim. Genet. 28: 103-115.

Flamand JRB, Vankan D, Gairhe KP, Duong H, et al. (2003). Genetic identification of wild Asian water buffalo in Nepal. Anim. Conserv. 6: 265-270.

Hoffmann I, Marsan PA, Barker JSF, Cothran EG, et al. (2004). New MoDAD Marker Sets to be Used in Diversity Studies for the Major Farm Animal Species: Recommendations of a Joint ISAG/FAO Working Group. In: Proceedings of 29th International Conference on Animal Genetics, Tokyo.

Huang P and Huang F (2006). Review and Prospect of Buffalo Scientific and Technical Development in China. Proceedings of the 5th Asian Buffalo Congress. Central Compilation and Translation Press, Nanning, China, 40-63.

Kimura M and Crow JF (1964). The number of alleles that can be maintained in a finite population. Genetics 49: 725-738.

Kumar S, Gupta J, Kumar N, Dikshit K, et al. (2006). Genetic variation and relationships among eight Indian riverine buffalo breeds. Mol. Ecol. 15: 593-600.

May B, Krueger CC, Eng C and Paul E (1995). Genes in Populations, Version 2.0: A Computer Program for Analysis of Genetic Data. Cornell Laboratory for Ecological and Evolutionary Genetics, Cornell University, Ithaca, New York.

Moioli B, Georgoudis A, Napolitano F, Catillo G, et al. (2001). Genetic diversity between Italian, Greek and Egyptian buffalo populations. Livest. Prod. Sci. 70: 203-211.

Nei M (1978). Estimation of average heterozygosity and genetic distance from a small number of individuals. Genetics 89: 583-590.

Ota T (1993). DISPAN: Genetic Distance and Phylogenetic Analysis. The Pennsylvania State University Park, Pennsylvania.

Raymond M and Rousset F (1995). Genepop (version 3.3): population genetics software for exact tests and ecumenicism. J. Hered. 86: 248-249.

Yang B, Zeng XLQ, Qin J and Yang C (2007). Dairy buffalo breeding in countryside of China. Ital. J. Anim. Sci. 6: 25-29.

Zhang Y, Sun D, Yu Y and Zhang Y (2007). Genetic diversity and differentiation of Chinese domestic buffalo based on 30 microsatellite markers. Anim. Genet. 38: 569-575. 